\title{
Effect of Ground Etching, Inset Feed and Substrate Height on Elliptically Shaped Patch Antenna
}

\author{
Ch. Amarnatha Sarma ${ }^{1}$, Sd. Inthiyaz ${ }^{2}$, B T P Madhav ${ }^{3}$ \\ ${ }^{1}$ Research Scholar, Department of ECE, Koneru Lakshmaiah Education Foundation, AP, India, sarma.chakrala@ gmail.com \\ ${ }^{2}$ Faculty, Department of ECE, Koneru Lakshmaiah Education Foundation, AP, India, syedinthiyaz@kluniversity.in \\ ${ }^{3}$ Faculty, Department of ECE, Koneru Lakshmaiah Education Foundation, AP, India
}

\begin{abstract}
Now a day the requirement of wireless communication increased rapidly with the demand for applications. This leads to the requirement of the design of compact wireless transceiver units. The antenna is one of the major blocks in the design which defines the compactness and efficiency of the unit. In this work, an elliptical patch antenna is designed on the FR4 substrate with $\varepsilon r=4.2$. Again the effect of etching the ground is studied. Also, the effect of inset feeding length studied. In the work, the author discussed various methods to convert a narrow band (NB) antenna into the ultra-wideband (UWB) antenna and wise versa. The proposed antenna can work in ultra band operation from 1 $\mathrm{GHz}$ to $12 \mathrm{GHz}$. The same proposed structure can work a wide band of $5.8 \mathrm{GHz}$ bandwidth from $2 \mathrm{GHz}$ to $7.8 \mathrm{GHz}$ with inset feed.
\end{abstract}

Key words: Elliptical patch, Etching ground, inset feeding, narrow band (NB) antenna, ultra wideband (UWB) antenna

\section{INTRODUCTION}

With the huge requirements of society, technology also developed rapidly. Especially in wireless communication systems, the growth is not having limits. With these unbounded limits, various wireless systems designs also increased. The major requirements are compacts, efficiency in terms of performance and power handling capabilities. The power handling capabilities can be improved by proper circuit design along with the antenna. But the performance of handling a wide band of allocation depends on the antenna design. The band of frequencies from $3.5 \mathrm{GHz}$ to $10.6 \mathrm{GHz}$ is approved as UWB by FCC in 2002. Various commercial applications come under this frequency band. So the design of the antenna in this band is a profitable challenge [1]. Various methods such as ground etching and providing slots in the patch are used to get this wideband and ultra-wideband antenna structures. S K Toshniwal et al. [2] proposed a compact patch antenna design for UWB applications. In that design, a modification is made in the ground structure. But the design complexity is more. A simple elliptical design is proposed in [3] which suffer from a poor S11 plot below $10 \mathrm{GHz}$. The selection of shape also shows the compactness. The elliptical, circular shape patches occupy less area than a rectangular patch for the same application band. This is one of the reasons so that circular or elliptical shapes are popular. Further, there is a freedom of parameter alteration is more in ellipse when compare with other standard structures. In the rectangular patch, only length and width dimensions can change, but by changing width the resonant frequency will be a shift. In a circular patch, the only radius dimension can able to change. Unlike the rectangular and circular there is some freedom for the designer to change the geometry of the elliptical patch so the size can be reduced [4]. In [5] a monopole antenna proposed with etching in the patch for wideband application with a complex design. A multiple band frequency antenna is proposed with the elliptical and fractal structure in [6] which not the UWB antenna. Various algorithms, structures, methods to improve the antenna performance are proposed and discussed in [7-14] all are having modification in the patch. One of the simple approaches is etching the ground can give ultra-wideband operation without altering the parch shape. The inset feed also plays an impartment role in the frequency response of the antenna. Changing the length and width of the inset feed the wideband characteristics also change [15-19].

From the above knowledge an elliptical patch antenna is proposing that can operate at $2.4 \mathrm{GHz}$ center frequency, the effect of etching ground on frequency response can be studied. Further, the effect of inset feed also studied. The simulation is done using commercial EM simulator HFSS. Section 1 states introduction and background, section 2 covers the design process, HFSS design model and simulation results, section 3 explains simulation results along with discussions and finally section 4 concludes the work.

\section{THE DESIGN PROCESS}

There are various approaches in the design of ellipticalshaped patch antennas such as analytical and genetic algorithms. In this paper, the area of the elliptical patch and the dimensions are calculated using the following metrics [6] 
Ch. Amarnatha Sarma et al., International Journal of Emerging Trends in Engineering Research, 8(7), July 2020, 3145 - 3149

Elliptical Patch $h_{\text {area }}=\pi r_{\text {aeff }} r_{\text {beff }}$

Here $r_{\text {aeff }}$ and $r_{\text {beff }}$ e effective lengths of semi major and minor axes respectively. They are calculated using

$r_{x e f f}=$

$\sqrt{r_{x}^{2}+\frac{2 h r_{x}}{\pi \varepsilon_{e f f}}\left[\ln \frac{r_{x}}{2 h}+1.41 \varepsilon_{e f f}+1.77\right]+\frac{h}{r_{x}}\left[0.268 \varepsilon_{e f f}+1.65\right]}$

In above equation when $\mathrm{x}=\mathrm{a}$ then effective major axis and with $\mathrm{r}=\mathrm{b}$ the effective minor axis is obtained.

Where $\varepsilon$ eff is

$\varepsilon_{\text {reff }}=\frac{\varepsilon_{r}+1}{2}+\frac{\varepsilon_{r}-1}{2} \sqrt{\left[1+12 \frac{h}{w}\right]^{-1}}$

$\mathrm{h}$ is the height of the substrate

$\mathrm{w}=$ width of minor axis

$\varepsilon_{\mathrm{r}}$ is dielectric constant of the substrate

\subsection{Elliptical Patch Antenna With Full Ground}

The antenna design is carried out using commercial EM tool HFSS. An elliptical patch having lengths of semi-major and semi-minor axes $r_{a}, r_{b}$. FR4 with $\varepsilon_{r}=4.2$ is used as substrate having dimensions with substrate height $1.6 \mathrm{~mm}$. The following Table. 1 shows the dimensions of the design, the design is shown in Figure 1.

Table 1: Design parameters of Elliptical patch antenna

\begin{tabular}{|l|l|l|}
\hline Parameter & Description & Dimension (mm) \\
\hline Ls & Substrate length & 40 \\
\hline $\mathrm{L}_{\mathrm{g}}$ & Feeder line length & 18.2 \\
\hline $\mathrm{W}_{\mathrm{s}}$ & Substrate width & 40 \\
\hline $\mathrm{W}_{\mathrm{g}}$ & Feeder width & 2 \\
\hline $\mathrm{h}$ & Substrate height & 1.6 \\
\hline $\mathrm{r}_{\mathrm{a}}$ & Semi major axis & 20 \\
\hline $\mathrm{r}_{\mathrm{b}}$ & Semi minor axis & 10 \\
\hline
\end{tabular}

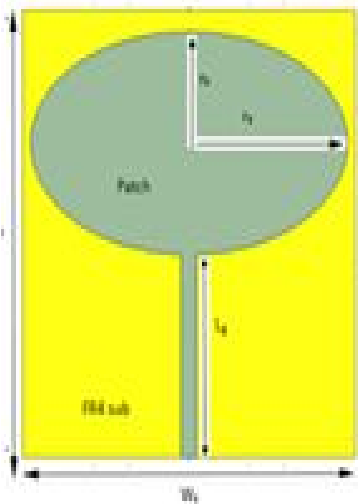

(a)

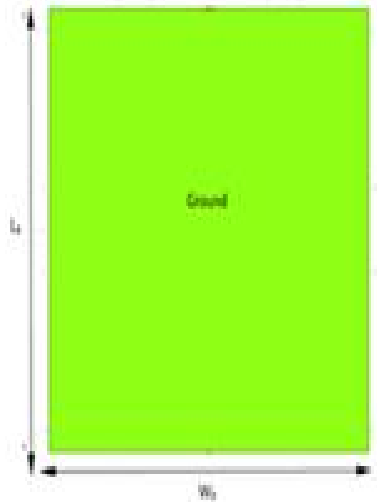

(b)
Figure.1: Elliptical patch antenna (a) Top view, (b) Bottom view,
The simulation result to the above model is, return loss (S11) and 3D radiation patterns are shown in Figure 2 (a) and (b). The S11 shows very poor values and the gains also very low

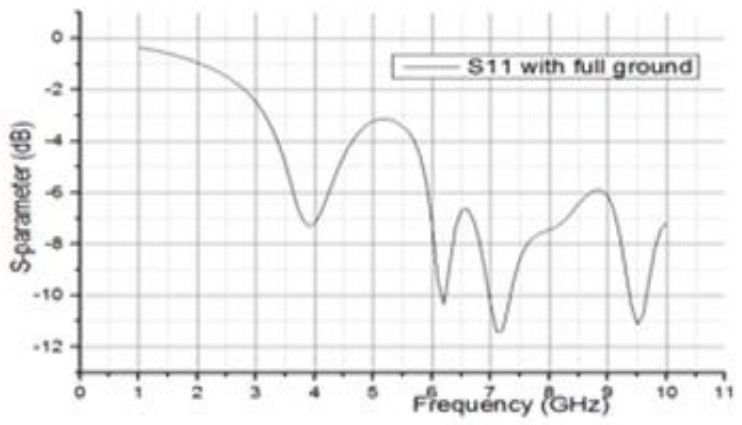

(a)
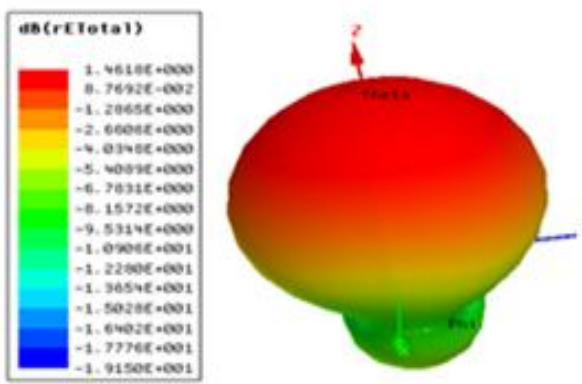

(b)

Figure 2:Elliptical patch antenna with full ground (a) Return loss (S11), (b) Radiation pattern

\subsection{Elliptical Patch Antenna With Etched Ground}

Elliptical patch antenna with more than $50 \%$ i.e. $22 \mathrm{~mm}$ ground etched shown in Figure 3. The resultant return loss (S11) and the radiation 3D plot is shown in Figure 4.

Their simulation results are, return loss (S11) and 3D radiation patterns are shown in Figure 4. From the results the antenna can an UWB antenna with band width from 1 to beyond $10 \mathrm{GHz}$, but little poor in radiation pattern.

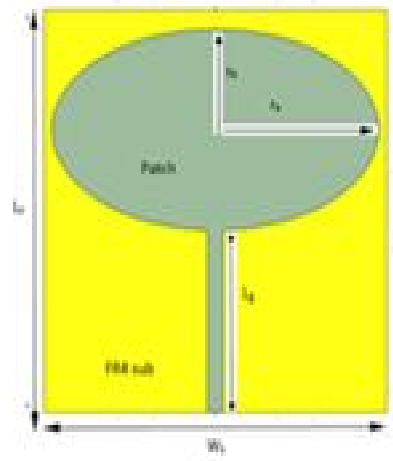

(a)

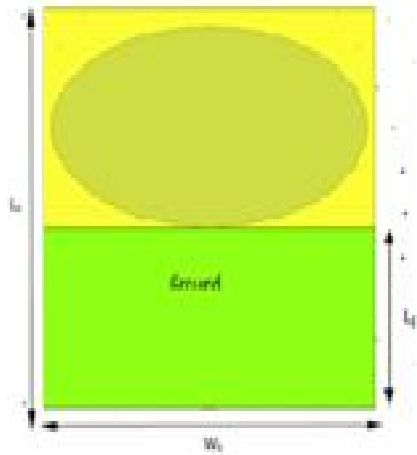

(b)
Figure 3:.Elliptical patch antenna with etched ground (a) Top view, (b) Bottom view 

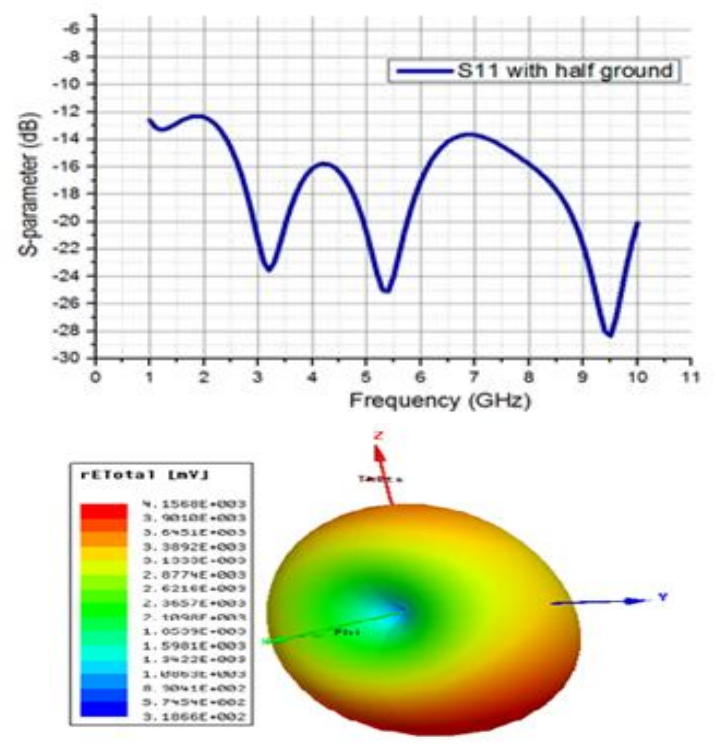

(b)

Figure 4:Elliptical patch antenna with etched ground (a) Return loss(S11), (b) Radiation pattern

\subsection{Effect Of Inset- Fed On Elliptical Patch Antenna With Etched Ground}

The input feed line is notched in to the patch, the notch width fallows squared cos function known as inset-fed. Taking an inset feed with insertion length of $\mathrm{L}_{\mathrm{i}} \mathrm{mm}$ and 0.3 $\mathrm{mm}$ width to above design the resultant HFSS model, return loss (S11) and radiation plot is shown in Figure 5.

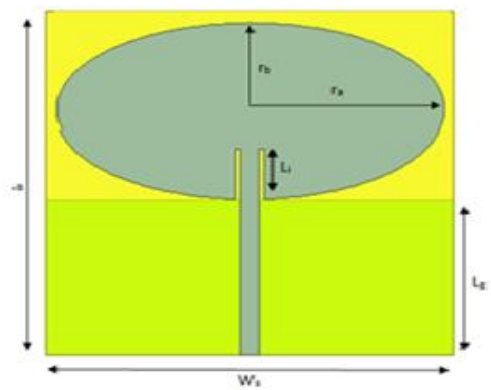

(a)

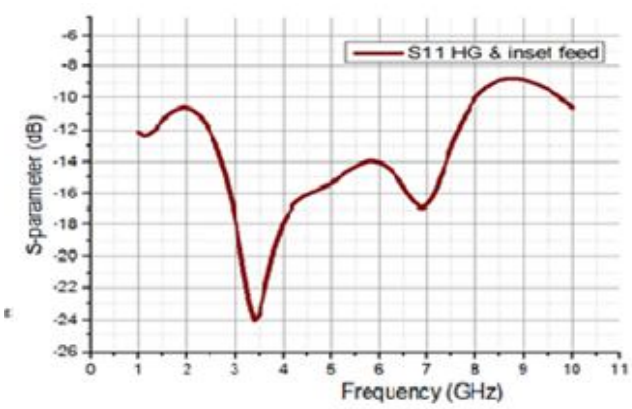

(b)
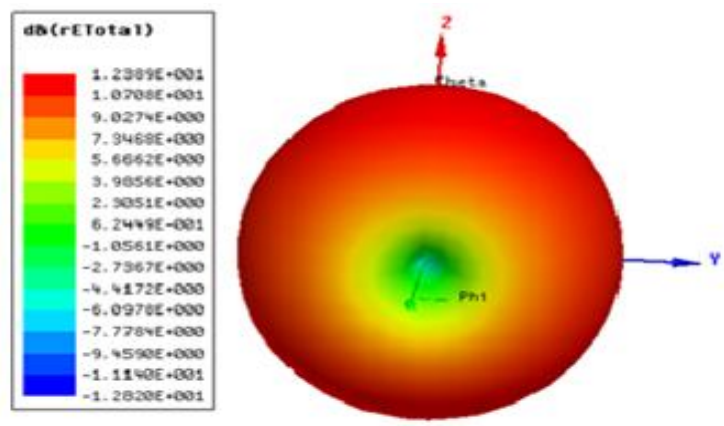

(c)

Figure 5: Elliptical patch antenna with etched ground (a) Top view (b) Return loss $(\mathrm{S} 11)$ (c) $3 \mathrm{D}$ radiation pattern

\subsection{Effect Of Substrate Height On Elliptical Patch Antenna With Etched Ground And Inset Feed}

The substrate height also plays an important role in antenna size. Large $\varepsilon_{\mathrm{r}}$ and substrate thickness are very efficient, but size is large. Smaller $\varepsilon_{\mathrm{r}}$ and substrate thickness are compact in size but lower efficient when compared. In this work the substrate heights are $\mathrm{h}=0.4 \mathrm{~mm}, 0.8 \mathrm{~mm}$, and $1.6 \mathrm{~mm}$ are verified with FR4 $\left(\varepsilon_{\mathrm{r}}=4.2\right)$ substrate. The same are compared with RT duroide $\left(\varepsilon_{\mathrm{r}}=2.2\right)$.

\section{SIMULATION RESULTS AND DISCUSSIONS}

By simulating the above designs the results are showing interesting relations. By etching ground plane the narrowband antenna is shown in becoming ultra-wideband antenna and also the unidirectional radiation pattern becomes Omni-directional. This is clearly explained in Figure 2 and Figure 4. By applying inset feed the ultrawideband antenna becomes a narrow band, but the radiation pattern is omni directional. This is shown in figure 5 .

The following Figure 6 shows the plot of return loss (S11) variation with changing the insertion feed length (Li). Figure 7 shows the compression plots of the elliptical patch with the full ground, etched ground, and etched ground with inset feed.

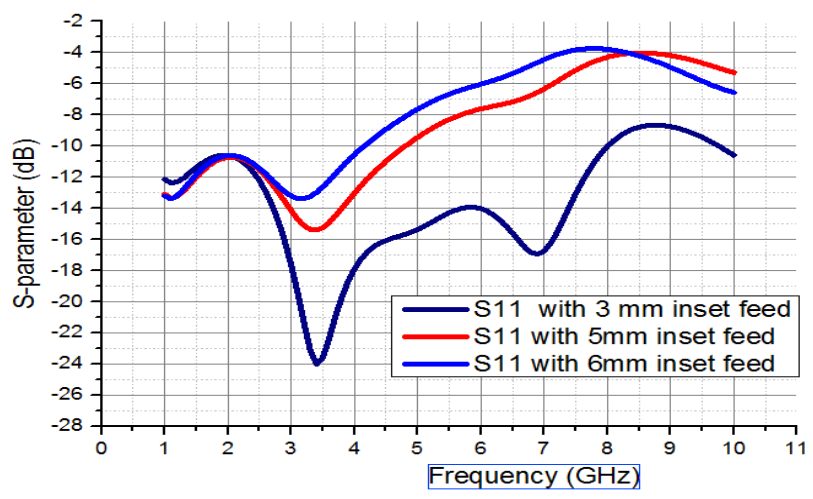

Figure 6:Variation in return loss (S11) with inset feed length $\left(\mathrm{L}_{\mathrm{i}}\right)$ 


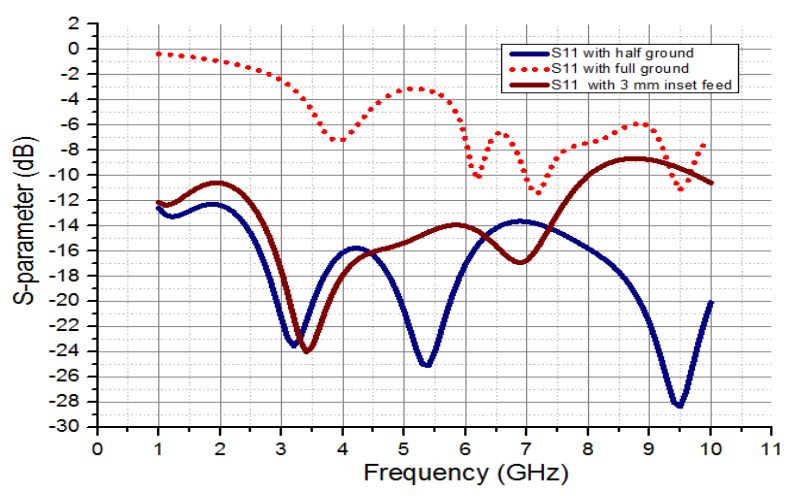

Figure 7: Comparison of return losses (S11) of elliptical patch antenna with full ground, etched ground and inset feed

The fallowing Figure 8 shows the variation of $\mathrm{S} 11$ by changing substrate from high $\varepsilon_{\mathrm{r}}$ ( FR4) to low $\varepsilon_{\mathrm{r}}$ (RT duroide) with different substrate heights.

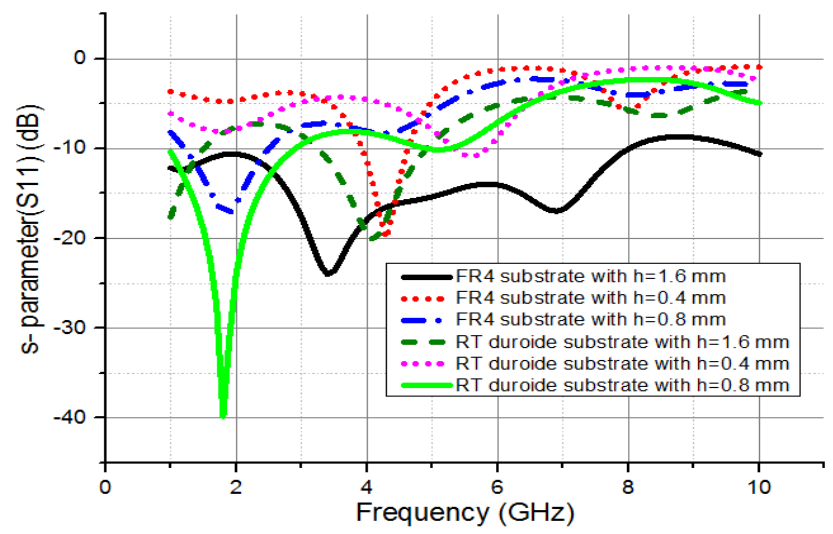

Figure 8:Comparison of return loss (S11) of elliptical patch antenna by changing substrate and substrate height.

From above Figure 6 and 7, one can conclude that ultra wide band operation can obtain with etched ground, but radiation pattern is not good which is shown in Figure 3(b). But with inset feed the radiation pattern is good as shown in Figure 5 (c). Figure 8 shows the compression of high $\varepsilon_{\mathrm{r}}$ ( FR4) with $1.6 \mathrm{~mm}$ shows good wide band characteristics than low $\varepsilon_{\mathrm{r}}$ (RT duroide) . But very good narrow band operation can be obtain with low $\varepsilon_{\mathrm{r}}$ (RT duroide) .

\section{CONCLUSSION}

From the above results, it is concluded that ultra-wideband operation can be obtained for an elliptical patch antenna by removing the ground blow the patch area. With this an omni directional radiation pattern also obtained. By using inset fed and high $\varepsilon_{\mathrm{r}}$ an omni directional radiation pattern can be obtain with small loss in bandwidth. The proposed antenna can be operated from $1 \mathrm{GHz}$ to beyond $10 \mathrm{GHz}$ with the etched ground, and a wide band of $2 \mathrm{GHZ}$ to $7.8 \mathrm{GHz}$ with an inset feed of $3 \mathrm{~mm}$ length. Further, this can be improved by changing the width of inset feed and etching in the ground.

\section{REFERENCES}

1. Noor M. Awad *, Mohamed K. Abdelazeez. Multislot Microstrip Antenna For Ultra-Wide Band Applications, Journal Of King Saud University Engineering Sciences, Volume 30, Issue 1, January 2018, pp 38-45

https://doi.org/10.1016/j.jksues.2015.12.003

2. S K Toshniwal, A Prajapati, K Ray, M R Ahmad, B H Ahmad, P Singh, A Bandyopadhyay. A Compact Uwb Antenna Design Using Modified Ground Plane, International Journal Of Innovative Technology And Exploring Engineering (Ijitee), Volume-8 Issue-10, August 2019, pp 615-618

3. Ch.Rama Krishna, Naga Ganesh.A and D. Durga Prasad. Design Of Elliptical Shaped Micro-Strip Patch Antenna For Ka Band, International Journal Of Research And Analytical Reviews, Volume 5 I Issue 3 I July - Sept 2018, Pp 961-965

4. M. M. Sharma, S. Yadav, A. Kumar, Y. Ranga and D. Bhatnagar. Compact Elliptical Microstrip Patch Antenna With Slotted Ground For Ku-Band Applications, IEEE Applied Electro magnetics Conference (AEMC), Kolkata, 2011, pp. 1-3 https://doi.org/10.1109/AEMC.2011.6256808

5. F. Guichi and M. Challal. Compact Uwb Monopole Antenna with Wimax/Itu Band Notch Characteristics, 2017 5th International Conference On Electrical Engineering - Boumerdes (ICEE-B), Boumerdes, 2017, pp. 1-4

6. Gupta M. Mathur, v. Multiband, Multiple Elliptical Microstrip Patch Antenna With Circular Polarization, Wireless Pers Commun 102, (2018), pp. 355-368

https://doi.org/10.1007/s11277-018-5843-x

7. Hooin Jung and Chulhun Seo, Analysis Of Elliptical Microstrip Patch Antenna Considering Attachment Mode IEEE Transactions on Antennas And Propagation, Vol. 50, No. 6, June 2002, pp 888-890,

8. Amit A. Deshmukh, Amita Mhatreb, Chinmay Kudoob, and Shefali Pawarb, E-Shape Microstrip Antenna Backed By Pairs Of Slots Cut Ground Plane For Wideband Response Procedia Computer Science volume 143, 2018, pp 101-107

https://doi.org/10.1016/j.procs.2018.10.357

9. Jerry V. Jose, A. Shobha Rekh, Jose M.J, Design Techniques For Elliptical Micro-Strip Patch Antenna And Their Effects On Antenna Performance International Journal Of Innovative Technology And Exploring Engineering (IJITEE) Issn: 2278-3075, Volume-8, Issue-12, October 2019 pp 2317-2326

10. S. K. Josan, J. S. Sohal and B. S. Dhaliwal, Design Of Elliptical Microstrip Patch Antenna Using Genetic Algorithms 2012 IEEE International Conference On Communication Systems (ICCS), Singapore, 2012, pp. $140-143$ https://doi.org/10.1109/ICCS.2012.6406125

11. Z. Zhang, S. Yang, M. Liu, S. Deng and I. Li,Design Of An UWB Microstrip Antenna With DGS Based On Genetic Algorithm 21 ${ }^{\text {st }}$ International Conference On 
Ch. Amarnatha Sarma et al., International Journal of Emerging Trends in Engineering Research, 8(7), July 2020, 3145 - 3149

Advanced Communication Technology (ICACT), Pyeongchang Kwangwoon Korea (South), 2019, pp. 228232

12. Jerry V. Jose, Aruldas S. Rekh, and Manayanickal J. Jose, Double-Elliptical Shaped Miniaturized Microstrip Patch Antenna For Ultra-Wide Band Applications Progress In Electro magnetics Research C, Vol. 97, , 2019, pp 95-107.

13. Jerry V. Jose, A. Shobha Rekh, Jose M.J.,DoubleElliptical Micro-Strip Patch Antenna For Higher Design Flexibility And Miniaturization, International Journal Of Engineering And Advanced Technology, Volume-9 Issue-1, October 2019, pp 6970-6976. https://doi.org/10.35940/ijeat.A2137.109119

14. Vijay Sharma, V. K. Saxena, K. B. Sharma, Deepak Bhatnagar, Radiation Performance Of An Elliptical Patch Antenna With Three Orthogonal Sector Slots, Romanian Journal Of Information Science And Technology Volume 14, Number 2, 2011, pp123-130

15. Vinayak Samarthay, Swarna Pundir, Bansi Lal, Designing And Optimization Of Inset Fed Rectangular Microstrip Patch Antenna (RMPA) For Varying Inset Gap And Inset Length International Journal Of Electronic And Electrical Engineering. Volume 7, No 9 (2014), pp. 1007-1013

16. S. Shankar and H. Chaurasiya, Inset Feed Microstrip Patch Antenna International Confe-rence On Computer, Communication And Control (IC4), Indore, 2015, pp. 1-3 https://doi.org/10.1109/IC4.2015.7375573

17. Ying Hu, D. R. Jackson, J. T. Williams and S. A. Long, A Design Approach For Inset-Fed Rectangular Microstrip Antennas IEEE Antennas And Propagation Society International Symposium, Albuquerque, NM, 2006, pp. 1491-1494 https://doi.org/10.1109/APS.2006.1710835

18. Kalavala Vamsi Krishna ${ }^{1}$, Habibulla Khan ${ }^{2}$, Ketavath Kumar Naik ${ }^{3}$, A Compact Rectangular Shaped Dipole Array Slot Microstrip Antenna with DGS for Multiband Application, International Journal of Emerging Trends in Engineering Research Volume 8. No. 2, February 2020 https://doi.org/10.30534/ijeter/2020/28822020

19. Lakshmi Charan Tangisetti ${ }^{1}$, T.V. Rama Krishna ${ }^{2}$, K. Kumar $\mathrm{Naik}^{3}$, A Compact UWB Microstrip Antenna With Hexagonal Circular Patch And Asymmetric CPW-Fed for On-body Applications, International Journal of Emerging Trends in Engineering Research Volume 8. No. 2, February 2020

https://doi.org/10.30534/ijeter/2020/49822020 